\title{
Measuring Student Engagement \& Commitment on Private Academic Institutions using Fuzzy Logic Expert System Metrics Applications
}

\author{
Evangelos Markopoulos ${ }^{1}$, Jarno Einolander ${ }^{2}$, Hannu Vanharanta ${ }^{2,3}$, Jussi Kantola ${ }^{2,3}$, \\ Ari Sivula ${ }^{2}$ \\ ${ }^{1}$ HULT International Business School, 35 Commercial Road, Whitechapel, E1 1LD London \\ United Kingdom. \\ ${ }^{2}$ University of Vaasa, Wolffintie 34, 65200 Vaasa, Finland \\ ${ }^{3}$ Poznan University of Technology, Plac Marii Skłodowskiej-Curie 5, 60-965 Poznań, \\ Poland
}

evangelos.markopoulos@faculty.hult.edu,jarno.einolander@gmail.com, hannu@vanharanta.fi, jussi.kantola@uwasa.fi, ari.sivula@gmail.com

\begin{abstract}
Even though academic knowledge is provided to academic institutions under very specific academic standards in teaching and research, the instruction's management can impact significantly the student engagement and commitment on receiving and utilizing such knowledge. To analyse this challenge, a Fuzzy Logic, expert system-based software application has been developed and applied on a private academic institution. In this research the institution participated with 40 undergraduate students, from 24 different countries from two different semesters on the same course. The technology measures the student engagement and commitment via the co-evolute methodology for knowledge elicitation. By utilizing this approach, the management of academic institutions can make development analysis based on concrete bottom-up results. The collective analysis of the test results clearly identifies where students see the needs for greatest development and how they view their current state of engagement.
\end{abstract}

Keywords: Student engagement $\cdot$ Commitment $\cdot$ Expert system $\cdot$ Private academic institution

\section{Introduction}

Astin [1] defined the term engagement in academic context as 'the amount of physical and psychological energy that the student devotes to the academic experience'. Later, Kuh [2] described student engagement as the time and effort students devote in educational activities that are empirically linked to desired outcomes and what institutions do to induce students to participate in these activities. Commonly, student engagement have been used to describe students' commitments in learning, their identification and belonging at their educational institution, as well as, describing their participation 
and activities in the school environment to accomplish desired outcomes, is associated with academic, social, and emotional learning outcomes [3].

\section{Student engagement and retention}

An increasing issue and major concern in universities around the world is the low student retention which has become one of the most serious topics in higher education. Low student retention rates have a negative effect on both the students and the academic institutions who devote huge amounts of resources to revert students from droppingout with incomplete education. Often dropout students have accrued large debts from their studies but leaving without a degree doesn't make it easy to get a well-paying job to pay them [4]. As higher education has a strong connection to the social, economic and political growth of the whole society its important this issue to be addressed collectively and not individually as it impacts the majority of the universities and not specific ones.

Student engagement or involvement within the educational institute can greatly influence student success and persistence. The term student engagement has become more popular in education during the recent decades, probably resulting from an increased understanding that certain intellectual, emotional, behavioral, physical, and social factors have effect in the learning process and social development [5]. Student engagement describes the time and effort students dedicate to activities that are related to the desired outcomes of the educational institutions and on what these institutions do to encourage students to participate in these activities [2]. According to Harper and Quaye [6], engagement is not just involvement or participation; it also necessitates feelings and sensemaking as well as being active. Studies have shown that students' psychological attachment to the university, that is, their commitment, can be a significant predictor of retention which affects many other attitudes and behaviors.

Based on previous research results, people who are committed to their studies are likely to perform better and are more likely to follow them through. Frequently research on retention has focused on academic abilities to predict the students' retention. However, research has also suggested that academic goals, institutional commitment, selfconfidence, social support, as well as, institutional selectivity, financial support, and social participation have positive effect on student retention. Students who are unable to develop these factors are more likely to drop out. Previous studies have indicated that the strongest factors on how students feel, is related to their academic skills, academic self-confidence and academic goals [7]. In addition, previous studies have shown that students who are committed to a particular university are more likely to graduate than those who do not show commitment to any particular institution.

Tinto [8] argues that students are more likely to stay and graduate when the institute, (1) expects them to succeed, (2) provides academic, social and personal support, (3) gives feedback regularly on their performance, (4) regards them as significant members of the institution (e.g., in frequent and high-quality interaction with the academics, the staff and other students), and most importantly (5) fosters learning. 
An important factor in the student's commitment is also the level of motivation for their studies. According to Skinner \& Pitzer [9] engagement is a result of motivation which promotes engagement if students needs for relatedness, competence, and autonomy are satisfied. Failure to fulfill these needs would lead to disengagement [9], which generates higher risks of later drop-outs [10]. Motivation that comes from students' desire to participate in the learning process has a positive impact on students' academic performance, learning strategy, adaptation and well-being [11]. Motivation in primary education, secondary education and higher education influences academic performance through study effort as a mediator [12].

\section{Student Engagement in Private Academic Institutions}

Private institutions operate under different management practices, strategies and standards from the state (government) institutions. The students pay higher tuition fees, and have expectations that could differ from what students expect in state institutions primarily in operations, support, administration management, infrastructure, and to an extend in the teaching quality, career development, student life, activities, etc. Many private academic institutions can be considered highly multicultural therefore the student engagement and commitment need to be approached from a cultural dimension as well, in both studying and learning. This cultural diversification extends also to the financial background of the students, were many might have secured professional careers while others might enter directly into their family business. Such students expect teaching and learning to be more practical, interactive, enjoyable, less research driven, more case driven and hands-on. This on the other hand can be a challenge for the academics who follow traditional academic teaching and research practices not quite aligned with the student's expectations and interests. Such cases, and not only, impact heavily the degree of student engagement and commitment, and become quite significant issues and concerns for the development of the strategic management and leadership on the institution's operations.

To further analyse this challenge, a Fuzzy Logic, expert system-based software application has been developed and applied on a private academic institution. In this research the institution participated with 40 undergraduate students, from 24 different countries from two different semesters on the same course. The technology measures the student engagement and commitment via the co-evolute methodology for knowledge elicitation.

\section{$4 \quad$ Evaluating student engagement}

The evaluation method used in this case-study utilizes a generic, Internet-based application environment called Evolute. The Evolute supports various purpose specific fuzzy logic based evaluation instruments [13], [14, [15]. The evaluation instruments are ontology-based, and they are used to acquire perception and collective understanding of different organizational resources. The instrument used in this study is called Helix Academic v2, and it is based on well-known models of student persistence and retention 
[16], [17]. The main models used in the creation of the framework for the ontology and the statements for the instrument application was Tinto's Student Integration Model [18], [19] and Bean's Student Attrition Model [20], [21]. The evaluation instrument uses self-evaluation in the assessment of different concepts through semantic entities, where in this case are statements. After the data collection, the system computes and visualizes the meaning of the knowledge input collected from the students. Such a fuzzy logic-based system reminds an expert's task of evaluating and reasoning based on linguistic information.

Helix Academic analyzes the goal commitment (personal goals) of the students. This is the degree students committed to the goal on obtaining their degree and how responsible are for their studies. Table 1 presents the key features for feedback categorization in Helix Academic.

Table 1. Helix Academic features.

\begin{tabular}{|c|c|}
\hline Feature & Description \\
\hline Goal progress & $\begin{array}{l}\text { The degree students feel that their studies are moving } \\
\text { forward helping them to accomplish their goals }\end{array}$ \\
\hline $\begin{array}{l}\text { Competence (personal } \\
\text { agency beliefs) }\end{array}$ & $\begin{array}{l}\text { The degree students feel about their performance and } \\
\text { competencies to study effectively and the attainabil- } \\
\text { ity of their goals. }\end{array}$ \\
\hline $\begin{array}{l}\text { Autonomy (centraliza- } \\
\text { tion) }\end{array}$ & $\begin{array}{l}\text { The degree students feel about the freedom from co- } \\
\text { ercion and their influence on their study environment } \\
\text { and decision making. }\end{array}$ \\
\hline Routinization & $\begin{array}{l}\text { The degree on how students feel whether their stud- } \\
\text { ies are exciting and challenging. }\end{array}$ \\
\hline $\begin{array}{l}\text { Social Integration (relat- } \\
\text { edness) }\end{array}$ & $\begin{array}{l}\text { The degree of student participation and integration to } \\
\text { a social group related to studies. }\end{array}$ \\
\hline Goal setting & $\begin{array}{l}\text { The degree students feel about course requirements } \\
\text { being on the right level. }\end{array}$ \\
\hline Responsive environment & $\begin{array}{l}\text { The degree students feel the study environment is re- } \\
\text { sponsive to promote effective learning. }\end{array}$ \\
\hline Learning support & $\begin{array}{l}\text { The degree students feel their university is providing } \\
\text { the support they need for their studies. }\end{array}$ \\
\hline Learning resources & $\begin{array}{l}\text { The degree students feel the university is providing } \\
\text { conditions and resources for learning. }\end{array}$ \\
\hline Distributive justice & $\begin{array}{l}\text { The degree students feel they are treated fairly and } \\
\text { recognized for their efforts. }\end{array}$ \\
\hline Teaching quality & $\begin{array}{l}\text { The degree students feel they are receiving quality } \\
\text { teaching at their university. }\end{array}$ \\
\hline Stressors & $\begin{array}{l}\text { The degree students feel there are things in the study } \\
\text { environment that may cause stress. }\end{array}$ \\
\hline Institution commitment & $\begin{array}{l}\text { The degree of student loyalty to the specific univer- } \\
\text { sity and their intent to graduate from it. }\end{array}$ \\
\hline Emotional attachment & $\begin{array}{l}\text { The degree of students feeling emotional attachment } \\
\text { and connection to this specific university. }\end{array}$ \\
\hline
\end{tabular}


Utility

Student satisfaction

Development

External commitments
The degree of how students recognize the future value, usability and utility of their studies and performance.

The degree on how students feel about various facets of satisfaction towards the university as a whole. The degree on how the students feel a sense of accomplishment and personal development.

The degree of personal binding variables external to the study environment (family, community etc.).

\section{Case-study}

A case study was carried out at the HULT International Business School, in London, UK. 110 students who attended a course on Creating Problem Solving in two semesters were asked to participate and access codes to the expert system were given to all. In the end, 40 students ( 36.4 of the participants) responded and completed the statements of the research application. The mean age of the respondents was 21 years of age. Sixtyfive (65\%) percent of the respondents were male, and 35\% female. All in all, there were 24 different nationalities in the case group.

The results of the case study are reported in the following figures. Figure 1 presents the results according to current state values, figure 2 is based on target state values, and figure 3 , is based on creative tension.

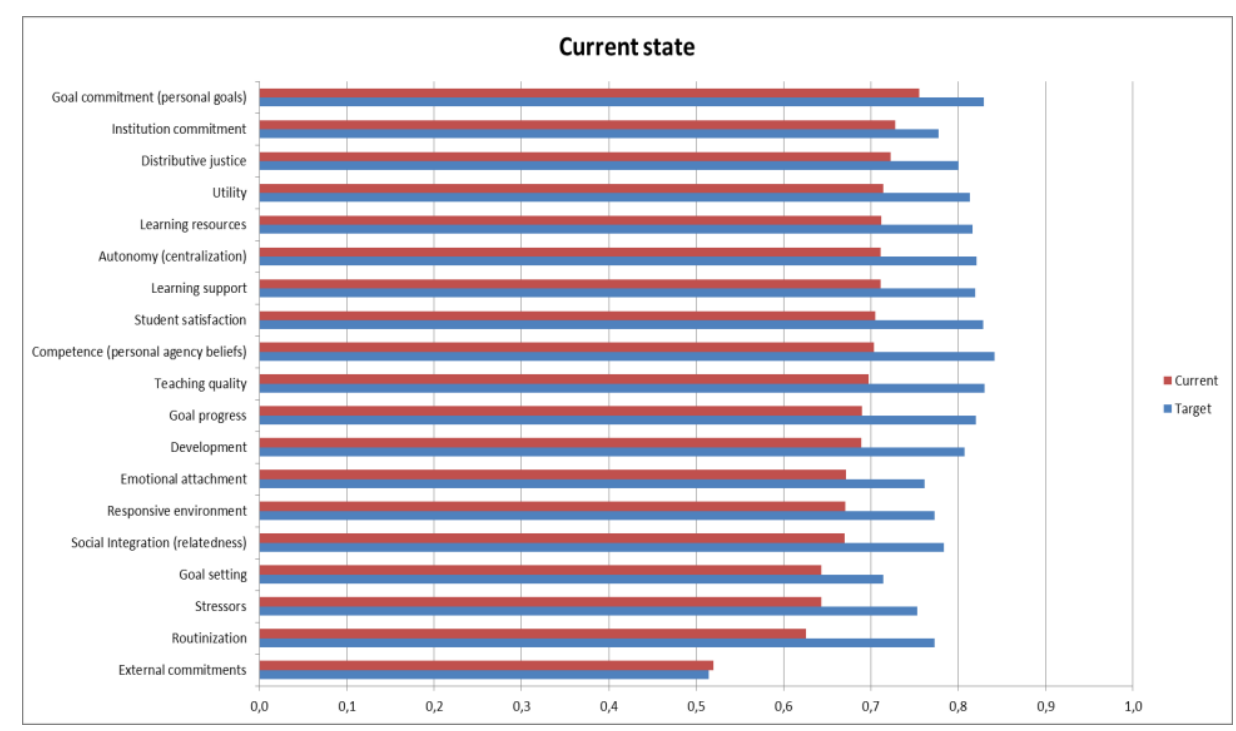

Fig. 1. Feature-level results based on current state values. 


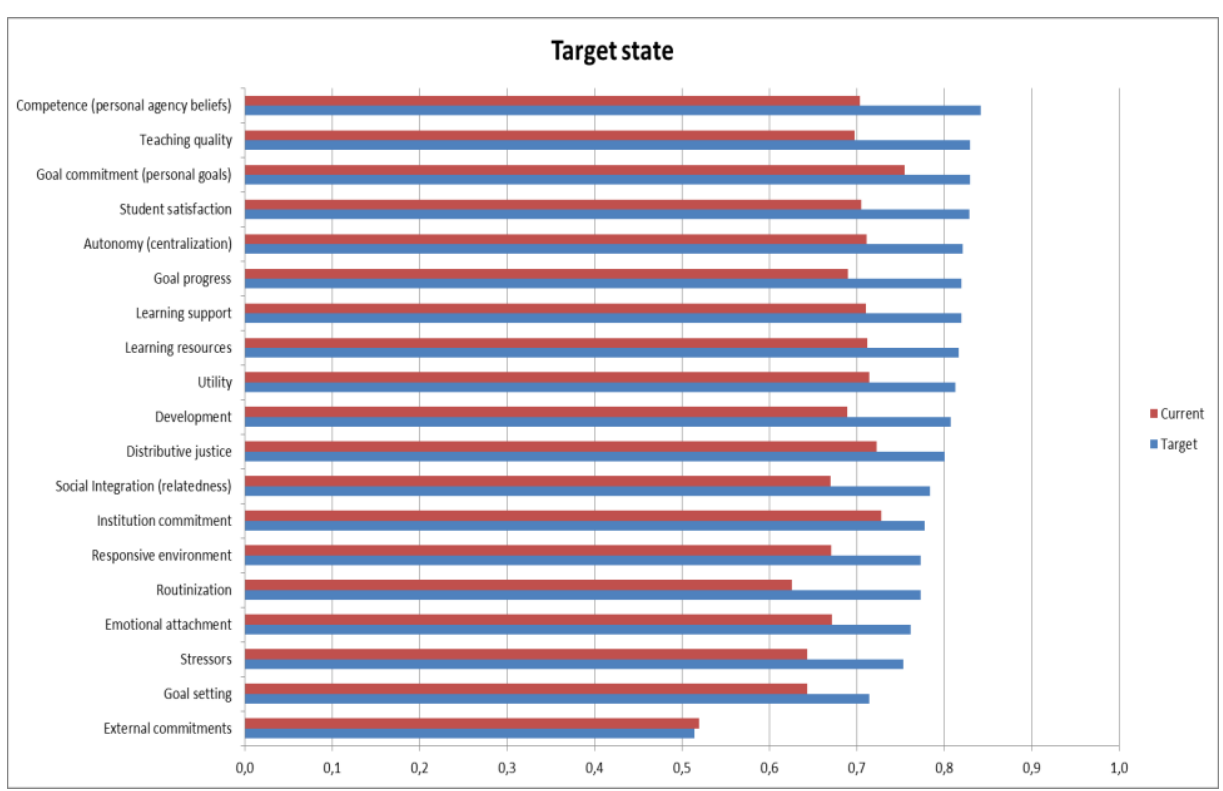

Fig. 2. Feature-level results based on target state values.

The results based on the creative tension show that the highest creative tension i.e. the gap between the state of collective current feelings and the target state, in the test group was in the feature of routinization. This feature assess the students feelings on how existing and challenging their studies are. Based on this result the respondents feel that the studies should provide more variety and be more challenging and stimulating. The next highest creative tension was in the feature of competence (personal agency beliefs). This feature describes the state of competence and performance of the students, as they perceive it and its match between the study environment's requirements. This shows that the respondents collectively feel they wish they would feel more competent regarding studying and would like to advance their study related skills and capabilities. The third highest creative tension was in teaching quality. This feature assesses e.g. the quality, consistency, professionalism, and interestingness of teaching staff and methods. The next highest creative tension was in the feature of goal progress describing the feeling of progress towards to accomplish the study related goals. In addition, the features of development and student satisfaction were at a relatively high level.

Interestingly these features were not regarded as highly based on target state evaluations. The target state indicates where the respondent would like to see improvement. In the target state evaluation, respondents express their own desires and feelings, according to their own situation and knowledge. Also, by looking at the results of the target state evaluations, it is possible to see how the respondents value each feature, in other words, which ones they think are the most important ones. 


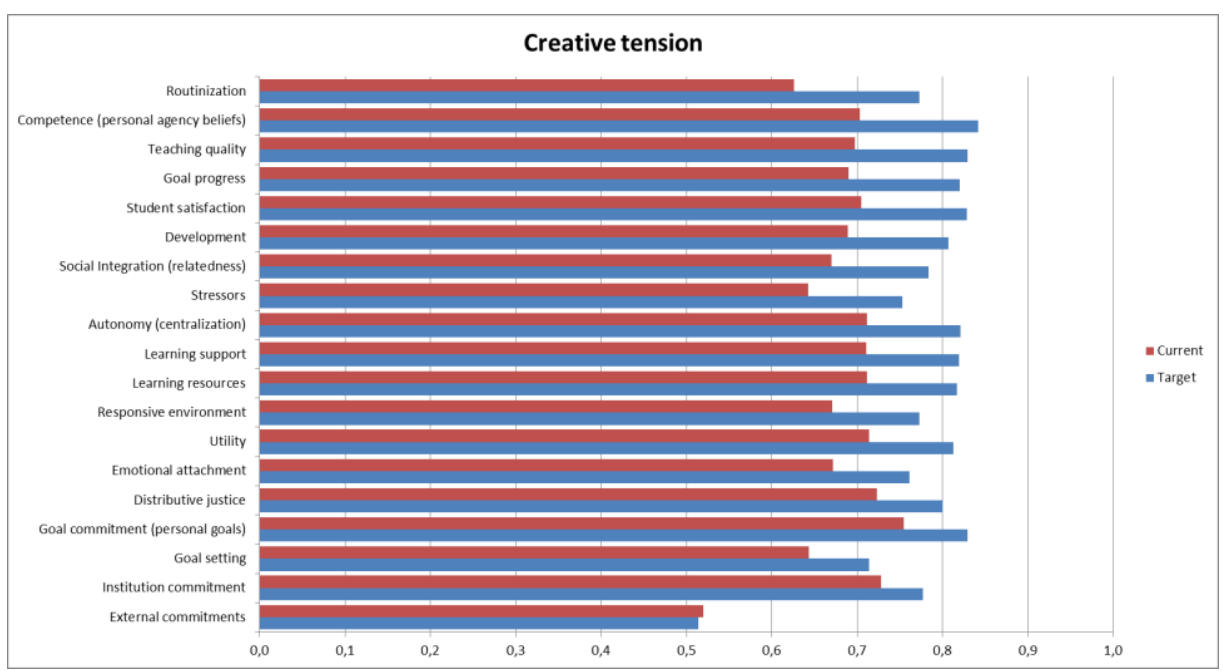

Fig. 3. Feature-level results based on creative tension values

Figure 4 presents the results according to current and target state values against the average values from other institutions. The darker red and blue bars illustrate the research results from this case study while the lighter bars represent average values from all research conducted with the instrument.

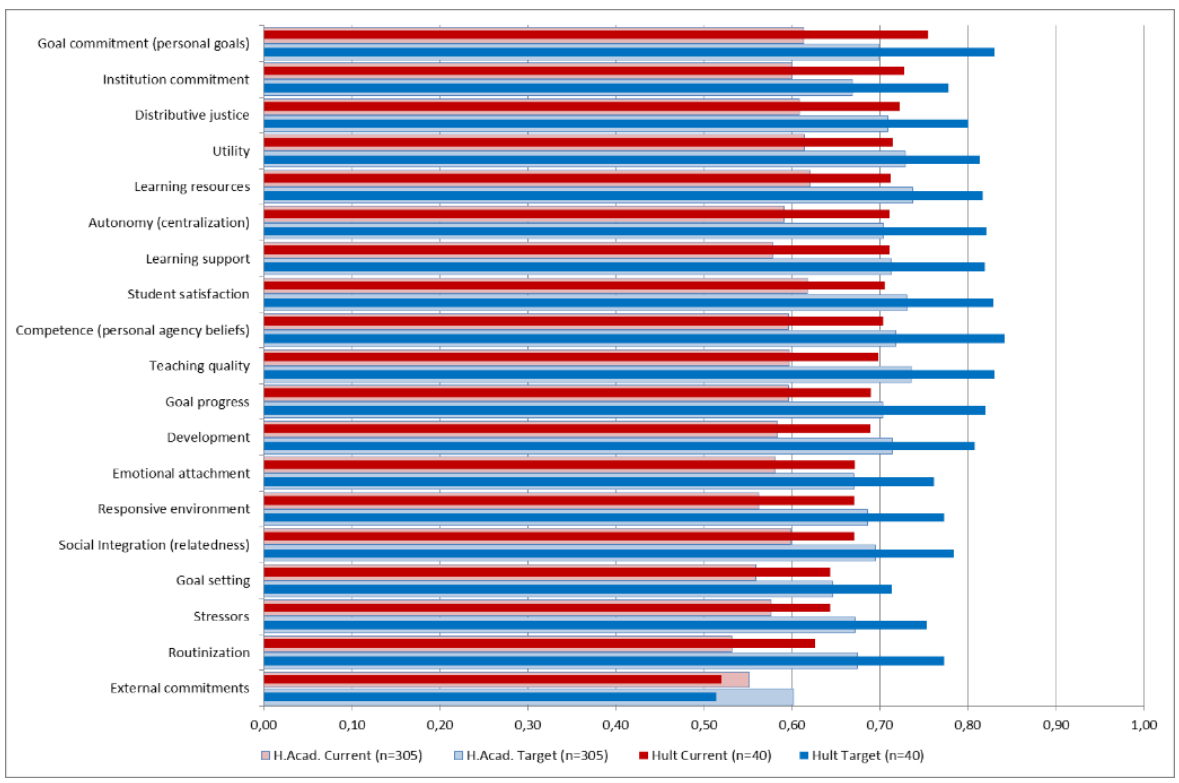

Fig. 4. Feature-level results compared between HULT and other institutions. 
According to the figure 4, it seems that the HULT case group scores higher in all of the features than the mean of all the case studies conducted with the research instrument, both in current and target states. Only in the feature of external commitments the HULT case had lower average scores.

In the later analysis, the results were subjected to Self Organization Map (SOM) analysis. The SOM maps were used to confirm the results. Figure 5 illustrates the six highest features based on target state evaluations. The color of the nodes in the component planes visualizes the value distribution of the variables. Warm colors (red, orange) indicate high values, while bluish colors indicate low values. Under each feature component, the color scales are presented as values. Based on SOM maps the results were similar to the results in figure 2. This kind of analysis was used in order to confirm the previous results (c.f. [22]).

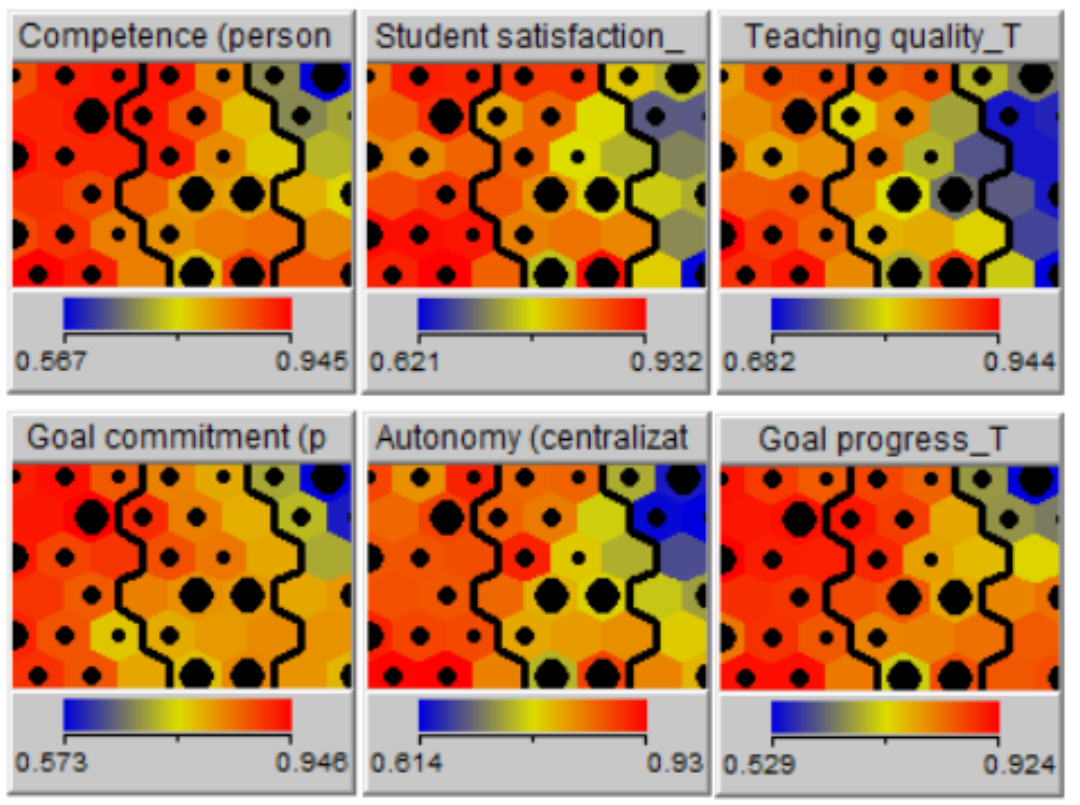

Fig. 5. A self-organized feature map (SOM) visualization of target state results

\section{Discussion}

The main goal of the assessment presented in this paper is to give university management new insight and information that can help them in their leadership and planning activities. By using the information gathered directly from the students, the management is more inclined to make effective developments plans because they can be based on such bottom-up information. These activities can, for example, help to advance the retention and satisfaction of the students. 
This type of analysis can be used to "benchmark" the institution and to compare it to others. Benchmarking also provides an interesting reference point for implementing and managing change. Comparisons to other groups and subsequent analysis can uncover good and useful practices utilized by other institutions.

Based on the results, the respondents feel a high degree of commitment to their goals to graduate from their current educational institute. The respondents feel this way much more highly than the long term average from multiple cases in different conventional universities. When looking at this case, the differences between current case results and long-term average values, the feature of goal commitment has also the biggest difference between them. These results are kind of expected in this case because HULT students aim higher, primarily due to their background.

Also, for example, the respondents feel a high level of distributive justice is prevalent in their educational institute, as well as they recognize the utility and the value of their studies more highly than the multiple case average. Only the external commitments are regarded at lower levels which seems correct based on the characteristics of the respondent group.

\section{Conclusions}

The research created data, information, and knowledge that can be used to support students in their commitment to complete their studies as well as to help the university, the academics and the administration to find out the drivers behind the so-called dropout problem and promote positive education performance. This is a new way to respect students' thinking for their studies, and it is also a modern way to lead and manage academic organizations.

The collective analysis of the test results clearly identified where students see the needs for greatest development and how they view their current state of engaging factors. As indicated in the research results, the respondents have creative tension in each feature which indicates that HULT has room to improve and narrow the distance from the current state to a desired, future state. This however cannot be considered critical as HULT students are above average from other institutions on both their current state (how they feel now) state and on their expectations for their future state (where they want to be). This indicates that HULT students are very active, have achieved a lot but want to achieve more. This creates space for improvement which can be achieved with a strategy based on the analysis of the results.

\section{$8 \quad$ Areas of further research}

HULT International Business School is an academic institution which operates in six cities and three continents. With undergraduate, post graduate and summer programs offered and delivered in London, Boston, San Francisco, Dubai and Shanghai, the institution can be considered one of global scale. This research studies the engagement and commitment of the students in the London Undergraduate campus only and 
involved 40 students from 24 different nationalities. The research will extend on understanding the results from each nationality group or individual in order to identify the students with the most or least engagement and commitment based on the country they come from and their educational culture which then can be related to social, financial and other elements that affect their engagement and commitment on their studies. Furthermore, the research will extend to the rest of the HULT campuses as students in Europe might have different engagement and commitment drives from students in the United States, Asia or Middle East while they all study in the same institution which provides the same education culture and operations processes.

The geographic distribution of the HULT campuses, the internationality and its global operations, can be considered ideal on studying student engagement and commitment in distance learning programs via e-learning. In this case, students also compose international classes while the programs can be delivered from different parts of the world under one institution.

As the future of education will be border less, distance less and available to all from all, it is crucial to understand the student's drives and needs while students operate in classes and environments by themselves or within cultural/national groups. Understanding the student's culture, backgrounds, goals and expectations in the international arena can not only contribute towards designing and executing effective, efficient and affordable educational programs, but also on creating processes and strategies towards a unified educational philosophy and culture.

\section{References}

1. Astin, A. W.: Student involvement: a developmental theory for higher education. Journal of College Student Personnel, 25(4), 297-308. (1984).

2. Kuh, G.D.: What student affairs professionals need to know about student engagement. Journal of College Student Development, 50(6). The Johns Hopkins University Press, 683-706. (2009).

3. Christenson, S. L., Reschly, A. L., Appleton, J. J., Berman, S., Spanjers, D. and Varro, P.: Best practices in fostering student engagement. Best Practices in School Psychology, 5, 10991120. National Association of School Psychologists Bethesda, MD. (2008).

4. Vedder, R., Gillen, A., Bennett, D., Denhart, M., Robe, J., Holbrook, T., Neiger, P., et al.: 25 Ways to Reduce the Cost of College. Center for College Affordability and Productivity (NJ1). ERIC. (2010).

5. Student Engagement. Retrieved from http://edglossary.org/ student-engagement/

6. Harper, S.R. and Quaye, S.J.: Beyond sameness, with engagement and outcomes for all. In: Harper, S.R.. Quaye, S.J. Student engagement in higher education. New York and London: Routledge, 1-15. (2009).

7. Lotkowski, V.A., Robbins, S.B., and Noeth, R.J.: The Role of Academic and Non- Academic Factors in Improving College Retention. ACT Policy Report. American Col- lege Testing ACT Inc. ERIC. (2004)

8. Tinto, V.: Promoting student retention through classroom practice. Enhancing Student Retention: Using International Policy and Practice, an international conference sponsored by the European Access Network and the Institute for Access Studies at Staffordshire University. Amsterdam, 5-7. (2003)

9. Skinner, E.A. and Pitzer, J.R.: Developmental dynamics of student engagement, coping, and everyday resilience. Handbook of research on student engagement. Springer, 21-44. (2012) 
10.Archambault, I., Janosz, M., Morizot, J., and Pagani, L.: Adolescent behavioural, affective, and cognitive engagement in school: Relationship to dropout. Journal of school health, 79(9), 408-415. (2009)

11. Lumsden, L.S.: Student Motivation To Learn. ERIC Digest, 92. ERIC Clearing- house on Educational Management. (1994)

12. Vansteenkiste, M., Zhou, M., Lens, W. and Soenens, B.: Experiences of autonomy and control among Chinese learners: Vitalizing or immobilizing? Journal of educational psychology, 97(3), 468. (2005).

13. Kantola, J.: Ontology-based resource management. Human Factors and Ergonomics in Manufacturing \& Service Industries, 19(6), 515-527. Wiley Online Library. (2009).

14. Kantola, J.: Organizational Resource Management: Theories, Methodologies, and Applications. CRC Press. (2015).

15. Kantola, J., Karwowski, W. and Vanharanta, H.: Managing managerial mosaic: the Evolute methodology. Electronic Globalized Business and Sustainable Development Through IT Management: Strategies and Perspectives, 77-89. (2011).

16. Einolander, J., Vanharanta, H., Chang, Y. S. and Kantola, J.: Comparing university students' commitment-a multicultural case study. Theoretical Issues in Ergonomics Science, 17, 3, 267283. Taylor \& Francis. (2016).

17. Einolander, J., Vanharanta, H., Kantola, J., Paliszkiewicz, J. and Madra-Sawicka, M. A Comparative Study of Student Engagement in two Polish Universities. Zeszyty Naukowe Politechniki Poznanskiej. Organizacja i Zarzadzaniev (Scientific Journals of Poznan University of Technology series of „Organization and Management”), 76, 87-98. (2018).

18. Tinto, V.: Dropout from higher education: A theoretical synthesis of recent research, Review of Educational Research. 89-125. (1975)

19. Tinto, V.: Leaving College: Rethinking the Causes and Cures of Student Attrition, University of Chicago Press, (1987).

20. Bean, J.P.: Dropouts and Turnover: The Synthesis and Test of a Causal Model of Student Attrition, ERIC, (1979).

21. Bean, J.P.: Student attrition, intentions, and confidence: Interaction effects in a path model, Research in Higher Education. 17, 291-320. (1982)

22. Kantola, J., Vanharanta, H., Laukkanen, I. and Piirto, A.: Revealing Asymmetries in Safety Culture through Proactive Vision. Chemical Engineering Transactions. 31, p. 319-324, (2013). 